\title{
The Potential Mechanisms of Berberine in the Treatment of Nonalcoholic Fatty Liver Disease
}

\author{
Xiaopeng Zhu ${ }^{1,2}$, Hua Bian ${ }^{1,2, *}$ and Xin Gao ${ }^{1,2}$ \\ 1 Department of Endocrinology and Metabolism, Zhongshan Hospital, Fudan University, Shanghai 200032, \\ China; zhuxp200@foxmail.com (X.Z.); zhongshan_endo@126.com (X.G.) \\ 2 Institute of Metabolic Disease, Fudan University, Shanghai 200032, China \\ * Correspondence: bianhuaer@126.com; Tel.: +86-136-8197-6102 \\ Academic Editors: Dong Kug Choi and Palanivel Ganesan \\ Received: 8 August 2016; Accepted: 29 September 2016; Published: 14 October 2016
}

\begin{abstract}
Nonalcoholic fatty liver disease (NAFLD) is a globally observed metabolic disease with high prevalence both in adults and children. However, there is no efficient medication available yet. Increased evidence indicates that berberine (BBR), a natural plant product, has beneficial effects on NAFLD, though the mechanisms are not completely known. In this review, we briefly summarize the pathogenesis of NAFLD and factors that influence the progression of NAFLD, and focus on the potential mechanisms of BBR in the treatment of NAFLD. Increase of insulin sensitivity, regulation of adenosine monophosphate-activated protein kinase (AMPK) pathway, improvement of mitochondrial function, alleviation of oxidative stress, LDLR mRNA stabilization, and regulation of gut microenvironment are the major targets of BBR in the treatment of NAFLD. Additionally, reduction of proprotein convertase subtilisin/kexin 9 (PCSK9) expression and DNA methylation are also involved in pharmacological mechanisms of berberine in the treatment of NAFLD. The immunologic mechanism of BBR in the treatment of NAFLD, development of berberine derivative, drug combinations, delivery routes, and drug dose can be considered in the future research.
\end{abstract}

Keywords: berberine; nonalcoholic fatty liver disease; mechanism; insulin resistance; adenosine monophosphate-activated protein kinase

\section{Introduction}

Nonalcoholic fatty liver disease (NAFLD), considered as the hepatic manifestation of the metabolic syndrome, is characterized by fat deposition in the cytoplasm of hepatocytes in the absence of overt alcohol consumption or other significant factors of liver injury. NAFLD is a globally metabolic disease with a wide spectrum of pathology ranging from simple steatosis to nonalcoholic steatohepatitis (NASH) and cirrhosis [1]. NAFLD affects $30 \%$ of the general adult population and up to $60 \%-70 \%$ of diabetic and obese patients [2-4]. Recent studies showed that NAFLD is becoming a major cause of hepatocellular carcinoma (HCC) in the United States [5], and some of HCC cases can occur in the absence of cirrhosis [6,7]. A more recent study showed that the annual incidence of NAFLD between 2003 and 2011 ranged from $2 \%$ to 3\% in a United States cohort of veterans, and the prevalence of NAFLD changed from $6.3 \%$ in 2003 to $17.6 \%$ in 2011 [8]. NAFLD is also closely associated with insulin resistance, metabolic syndrome, and type 2 diabetes. The relationship between NAFLD and cardiovascular disease among the general population has been increasingly confirmed $[9,10]$. Additionally, recent evidence elucidates that patients with NASH are more sensitive to developing colorectal adenomas and advanced neoplasms [11]. 
So it is necessary to develop an efficient therapy for fighting against or preventing NAFLD. Although some antioxidants, insulin sensitizers, and lipid-lowering drugs-such as vitamin E, metformin, thiazolidinediones, and statins - have been investigated and show a certain effect on reducing liver fat content and liver enzymes, improving partial liver histological lesions and lowering the score of NAFLD, they have no significance in alleviating liver fibrosis [12,13]. Therefore, there is still no approved pharmacological therapy for NAFLD available at present [14]. Recently, the effect of obeticholic acid, a farnesoid $X$ nuclear receptor ligand, has been conducted in adult patients with non-alcoholic steatohepatitis [15]. The result showed that oral administration of obeticholic acid alleviated the liver histology of non-alcoholic steatohepatitis, suggesting the potential efficacy of obeticholic acid in the treatment of NAFLD [15]. However, the benefits and safety of obeticholic acid in the long term are still unknown, which should be elucidated in the future.

Berberine (BBR, $\mathrm{C}_{20} \mathrm{H}_{18} \mathrm{NO}_{4}$ ), an isoquinoline quaternary alkaloid, has been widely used in Ayurvedic and Chinese Medicine for hundreds of years [16], which is extracted from Coptis chiensis, Rhizoma coptidis, Hydrastis canadensis, etc. [17]. BBR is a natural plant product which is commonly used to treat diarrhea and gut infections in clinical practice. Additionally, a wide spectrum of additional pharmacological effects of BBR - containing the treatment of central nervous system disorders, diabetes, cancer, cardiovascular disease, depression, hypertension, hypercholesterolemia, etc.- -have been discovered [10,18,19]. Among them, a number of effects of BBR like regulation of metabolism disorder, increase of insulin sensitivity, lipid-lowering effect, and improving glycometabolism, which may partially indicate its potential role in treatment of NAFLD, attract us to pursue it as a novel natural drug for NAFLD. However, the mechanism of BBR in the treatment of NAFLD has not yet been conclusively determined. With much excellent work done towards this end, great progress has been made in the mechanism of BBR in the treatment of NAFLD, which significantly increases our comprehension of BBR.

In this review, we briefly summarize the pathogenesis of NAFLD and the targets of BBR in the treatment of NAFLD, and focus on the potential mechanisms of BBR in the treatment of NAFLD under the categories of insulin resistance, adenosine monophosphate-activated protein kinase (AMPK) pathway, mitochondrion dysfunction, serum cholesterol-lowering effect, gut microenvironment, and other mechanisms.

\section{The Pathogenesis of NAFLD and the Targets of BBR in the Treatment of NAFLD}

NAFLD initiates with aberrant accumulation of triacylglycerol (TG) in hepatocytes. Both increased input or synthesis of TGs and decreased output of TGs promote the progression of NAFLD. Increased input or synthesis of TGs includes increased dietary intake, increased lipolysis from adipocytes, and increased de novo lipogenesis in hepatocytes, which can be induced by hyperinsulinemia, hyperglycemia, obesity, and fructose ingestion [20-22]. Decreased output of TGs includes reduced $\beta$-oxidation in mitochondria, reduced extra-hepatic transport of TG in the form of very low-density lipoprotein (VLDL) [20]. Then, TGs accumulated in hepatocytes induce simple steatosis. Long-term hepatic steatosis can develop to NASH, the mechanisms of which include oxidative stress, maladjustment of the unfolded protein response, endoplasmic reticulum (ER) stress, lipotoxicity, and dysbiosis in gut [23-26]. Long-term hepatocyte death of NASH contributes to fibrosis. NASH-related fibrosis can lead to cirrhosis, and cirrhosis can develop into hepatic carcinoma (Figure 1A). Additionally, other factors also influence the progression of NAFLD, which have been briefly summarized in Figure 1B. 


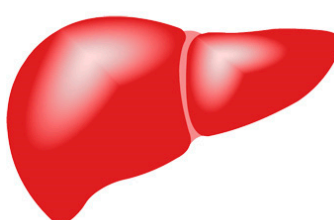

Normal liver

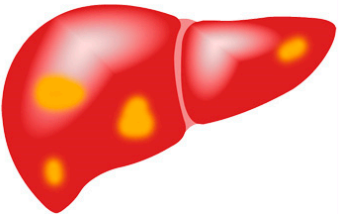

Steatosis

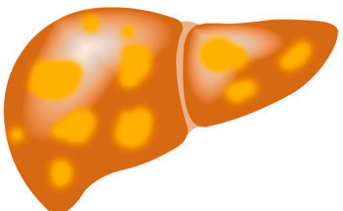

$\mathrm{NASH}$

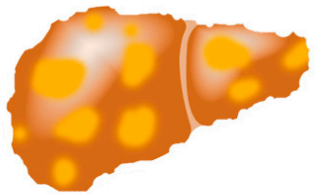

Cirrhosis

A

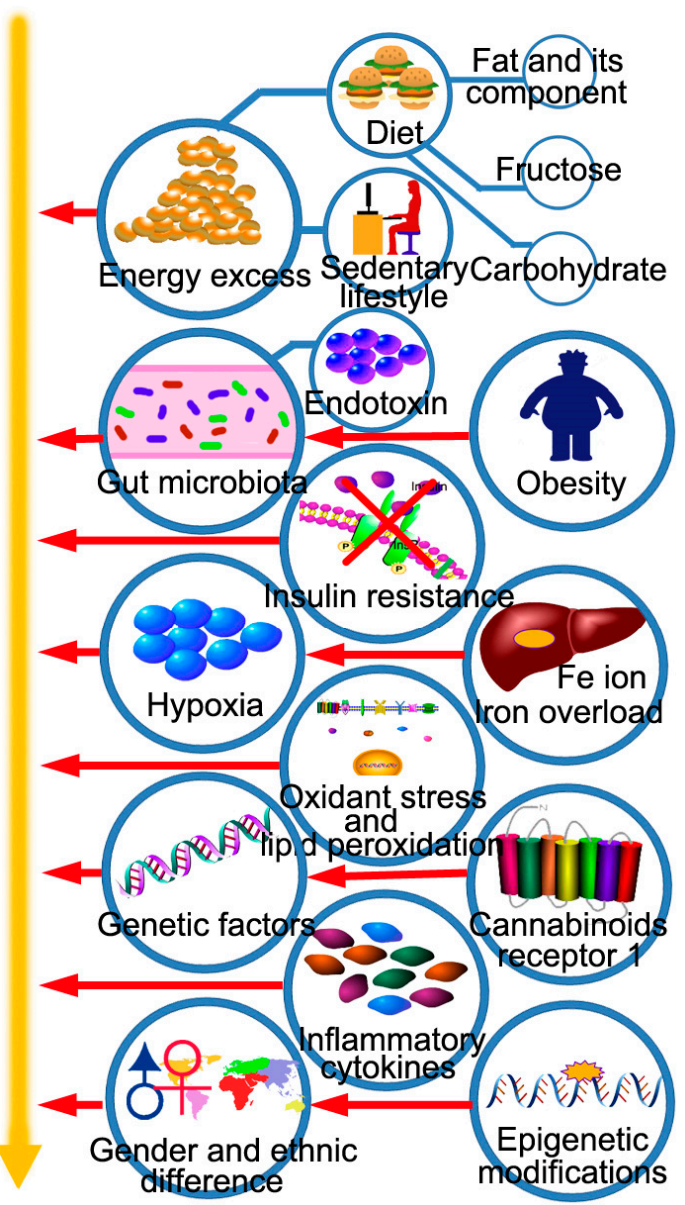

B

Figure 1. The disease spectrum of NAFLD and the factors that influence the progression of NAFLD. (A) The spectrum of NAFLD ranges from simple steatosis to NASH and cirrhosis. Simple steatosis is characterized by the ectopic accumulation of lipid droplets in the cytoplasm of hepatocytes without hepatocyte injury, inflammation, and fibrosis histologically. Steatosis is self-limited and can be reversed by lifestyle modifications. Steatosis can develop to NASH, which differs from simple steatosis in the presence of hepatocyte injury, inflammation, and fibrosis. Long-term NASH leads to cirrhosis. In NASH-related cirrhosis, normal liver structure is damaged and replaced by type 1 collagen, and pseudolobules are formed; (B) The factors that influence the progression of NAFLD include energy excess, obesity, insulin resistance, genetic factors, gender and ethnic difference, gut microbiota, hypoxia, oxidative stress and lipid peroxidation, inflammatory cytokines, liver iron overload, endogenous cannabinoids receptor 1, and epigenetic modifications. Energy excess includes diet and sedentary lifestyle.

\section{The Potential Mechanisms of Berberine in the Treatment of NAFLD}

Both animal experiments and clinical trials suggest the potential benefit effect of BBR on NAFLD. BBR significantly decreases serum lipid levels both in rats and patients and induces a mild weight loss in obese patients [27]. Additionally, BBR slightly reverts lipid profile in Caucasian subjects with low cardiovascular disease risk [28]. We carried out a randomized, parallel controlled, open-label clinical trial (NCT00633282) including 184 patients to estimate the efficacy of BBR in patients with NAFLD and found that treatment with BBR plus lifestyle intervention greatly reduced hepatic fat content and improved body weight, homeostatic model assessment for insulin resistance (HOMA-IR), and serum lipid profiles, compared with lifestyle intervention alone [29]. Nevertheless, the precise mechanism underlying these effects is not yet completely uncovered [30]. 
Generally, both increased synthesis and decreased output of TGs are the targets of BBR in the treatment of NAFLD. BBR can suppress de novo lipogenesis, increase fatty acid $\beta$-oxidation, and increase extra-hepatic transport of TG in the form of VLDL in liver. Additionally, liver inflammation and other pathophysiological processes such as oxidative stress, ER stress, and dysbiosis in the gut are also the targets of BBR in the treatment of NAFLD. So, BBR improves NAFLD via targeting multiple pathophysiological procedures.

\subsection{BBR Improves Insulin Resistance via Multiple Ways}

There is a synergistic action between hyperlipoidemia and insulin resistance. When patients develop insulin resistance, the glucose-lowering effect of insulin weakens, while the lipogenesis effect of insulin still works, which results in the progression of NAFLD [31]. Increased evidence suggests that BBR can improve insulin resistance [32-38], and several potential mechanisms have been discovered (Figure 2A-E).

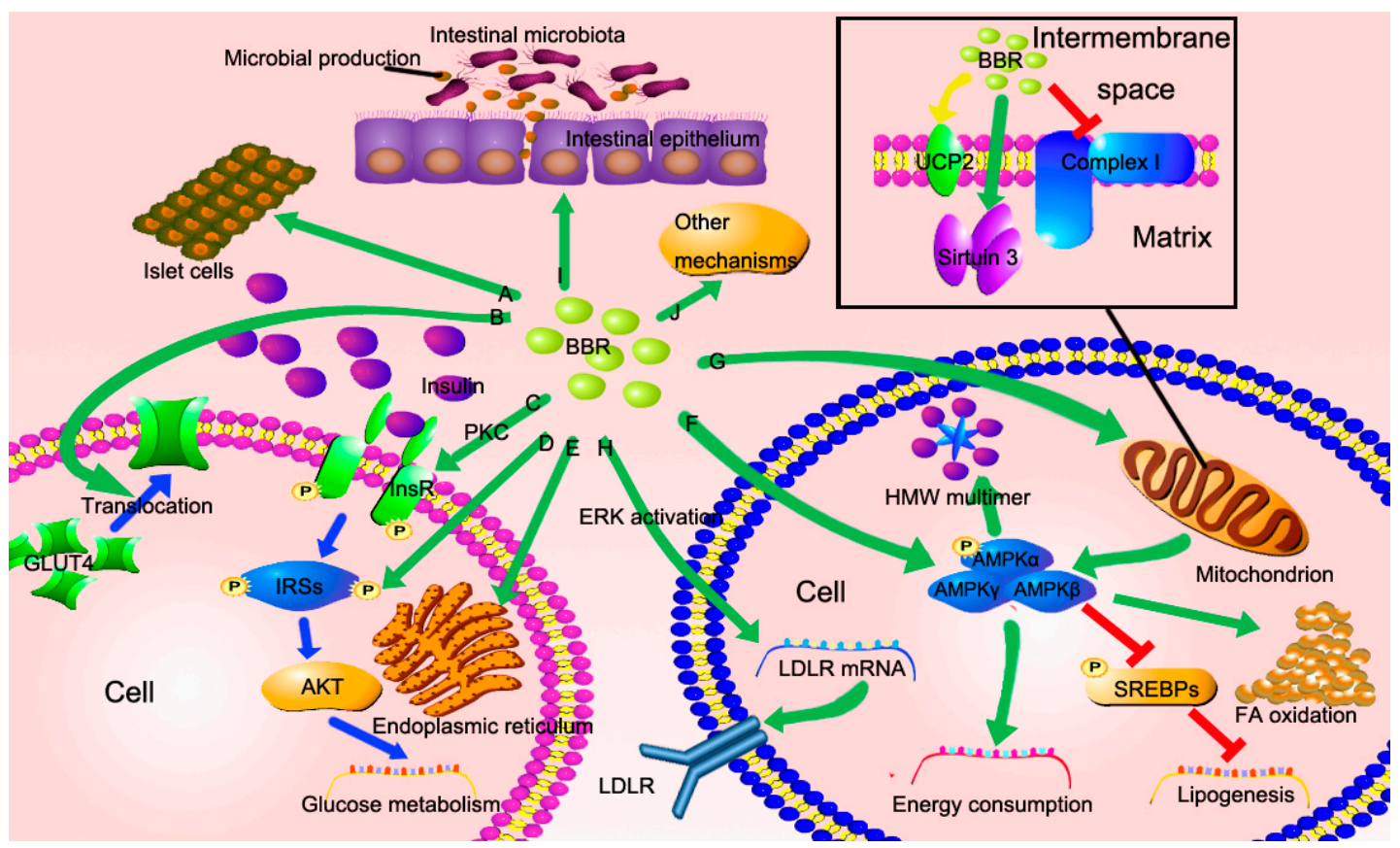

Figure 2. The potential mechanisms of berberine in the treatment of NAFLD. (A-E) BBR improves insulin resistance via directly triggering insulin secretion, increasing IRSs expression, increasing InsR expression through PKC activation, inducing GLUT4 translocation to cell membrane and decreasing ER stress; (F) BBR activates AMPK in both direct way and indirect way. The activation of AMPK decreases lipogenesis, increases energy consumption, promotes FA oxidation, and triggers adiponectin multimerization to HMW multimer; (G) BBR inhibits mitochondrial respiratory complex I and enhances AMP/ATP ratio, resulting in the activation of AMPK. In addition, BBR increases the expression of sirtuin 3, improving mitochondrial function and alleviating oxidative stress. It is controversial whether BBR induces UCP2 expression; (H) BBR stabilizes LDLR mRNA and increases LDLR expression, which depends on ERK activation; (I) BBR regulates intestinal microbiota, reduces the entry of microbial productions, and repairs gut permeability caused by damaged tight junctions; (J) Other mechanisms containing reduction of PCSK9 expression and DNA methylation may be involved.

BBR directly induces insulin secretion in HIT-T15 cells, pancreatic islets, and normal mice [39]. Another route of BBR in the regulation of insulin resistance is via increasing glucose transporter 4 (GLUT4) translocation to the cell membrane in myotubes and decreasing lipid mass in adipocytes [32]. In addition, insulin signaling pathway can also be improved by BBR. Treatment with BBR increases expression of insulin receptor (InsR) mRNA and protein both in rat L6 cells and human hepatocytes 
(HepG2 and Bel-7402) in a dose- and time-dependent manner [36]. Further investigation indicates that the increased InsR gene expression is via activation of its promoter by protein kinase C (PKC) [36]. Insulin receptor substrate-2 (IRS-2) is another target of BBR. Treatment with BBR in rats upregulates IRS-2 messenger RNA (mRNA) and protein, which serves a significant role in the insulin signaling pathway [38]. BBR modifies Ser/Thr phosphorylation of IRS-1 and downstream Protein kinase B (PKB), also called AKT, leading to improved insulin signaling cascade [37]. Adiponectin, an adipokine secreted by adipocytes, is identified to increase insulin sensitivity [40]. Increased expression of adiponectin enhances insulin sensitivity via activation of AMPK [40,41]. Adiponectin possesses three multimers-trimer (LMW), hexamer (MMW), and high-molecular-weight (HMW) multimer-and the HMW adiponectin possesses more activity [42,43]. BBR reduces the adiponectin expression, but enhances adiponectin multimerization to HMW multimer via activation of AMPK, thus leading to enhanced insulin sensitivity [44].

The anti-inflammatory potential and anti-ER stress effect of BBR may be involved in reversing insulin resistance. Interleukin-6 (IL-6) and tumor necrosis factor- $\alpha$ (TNF- $\alpha$ ) induced by palmitate, which lead to inflammation and insulin resistance, are effectively diminished by BBR in a dose-dependent manner [37]. Further, BBR reduces cyclooxygenase-2 (COX-2) protein, decreases phosphorylation state of c-Jun N-terminal kinase 1 (JNK1) and reduces the mRNA levels of proinflammatory cytokines, resulting in an anti-inflammation effect $[45,46]$. Because inflammation also plays a critical role in the pathogenesis of NAFLD, the anti-inflammatory effect of BBR can alleviate the condition of NAFLD directly. Study showed that the expression of oxygen-regulated protein 150 (ORP150) was reduced when pretreated with BBR in HepG2 cells, while the phosphorylation of PKR-like eukaryotic initiation factor $2 \alpha$ kinase (PERK) and eukaryotic translational initiation factor $2 \alpha$ (eIF2 $\alpha$ ) was blocked accompanied by increased phosphorylation of IRS-1 Tyr and AKT Ser473 [47]. ORP150, PERK and eIF2 $\alpha$ are considered as the molecular markers of ER stress [47]. A more recent study suggested that the beneficial effect of BBR on ER stress induced lipogenesis was partly via the activating transcription factor 6 (ATF6)/sterol regulatory element-binding protein-1c (SREBP-1c) pathway in vitro [48].

Because of the synergistic effect between NAFLD and insulin resistance, improvement of fat metabolism reverts insulin resistance to some extent. Peroxisome proliferator-activated receptors (PPARs) regulate fat metabolism and energy homeostasis involving $\beta$-oxidation and adipogenic processes [35,49]. Study indicated that BBR reduced PPAR $\gamma$ and fatty acid translocase (FAT) protein expressions, and decreased fatty acid uptake, thus leading to improved glucose uptake in myotubes [35]. Moreover, the expression of PPAR $\gamma 2, \mathrm{C} / \mathrm{EBP} \alpha$, adiponectin, and leptin mRNA was downregulated by BBR in human preadipocytes and metabolic syndrome patients, suggesting that improved fat storage and adjusted adipokine profile play a role in restoring insulin resistance [50].

\subsection{BBR Reduced Lipid Accumulation via Regulating AMPK Phosphorylation}

AMPK is a kind of highly conservative, heterotrimeric, serine threonine protein kinase, which consists of a catalytic subunit, AMPK $\alpha$, and two regulatory subunits, AMPK $\beta$ and AMPK $\gamma$ [51,52]. AMPK is considered as a pivotal role in systemic energy metabolism [51,53]. Study showed that BBR acutely activated AMPK in both L6 myotubes and 3T3-L1 adipocytes [32]. Both central and peripheral administration of BBR induce AMPK activity [54]. Increased evidence indicates that AMPK was activated by BBR via increasing phosphorylation of AMPK [32,54,55]. The AMPK activity induced by BBR does not depend on the activity of either liver kinase B1 (LKB1) or calmodulin-mediated kinase kinase $\beta($ CaMKK $\beta)$ [56]. LKB1 and CaMKK $\beta$ are the main kinases that activate AMPK via phosphorylation of Thr172 [57-59]. However, it is controversial whether BBR activates AMPK in a direct way. Evidence indicates that treatment with BBR inhibits mitochondrial respiratory complex I and increases AMP/ATP ratio, thus leading to the activation of AMPK [56,60]. So, it is possible that there is both a direct and indirect way contribute to the activation of AMPK by BBR (Figure 2F). 
The activation of AMPK downregulates lipogenesis associated genes, and upregulates energy consumption, resulting in reduced lipid accumulation and improved liver condition. The phosphorylation of AMPK directly suppresses activity of SREBP-1c and -2 via Ser372 phosphorylation and blockades SREBP-1c cleavage and nuclear translocation, leading to decreased SREBP-1c target gene, involving acetyl-CoA carboxylase 1 (ACC1), fatty acid synthase (FAS), and stearoyl CoA desaturase 1 (SCD1) transcription and translation [33]. In addition, the mRNAs of two key enzymes of cholesterol biosynthesis, 3 '-hydroxylmethyl glutaryl coenzyme A synthetase (HMGCS) and 3'-hydroxylmethyl glutaryl coenzyme A reductase (HMGCR), are also reduced by activation of AMPK, which is consistent with decreased SREBP-2 [33]. Therefore, reduced expression of ACC1, FAS, SCD1, HMGCS, and HMGCR leads to decreased triglyceride and cholesterol biosynthesis, thus improving hepatic steatosis [33]. Furthermore, BBR metabolite, columbamine, also presents the potential effects on reducing TG level, which is also via activation of AMPK [61].

\subsection{BBR Improves Mitochondrial Function and Alleviates Oxidative Stress}

As mentioned above, BBR can block mitochondrial respiratory complex I. However, recent study demonstrated that $B B R$ reduced mitochondrial reactive oxygen species (ROS) generation and improved hepatic mitochondrial dysfunction in obese rats probably via activating the mitochondrial sirtuin (SIRT3) [62]. Furthermore, BBR ameliorates mitochondrial dysfunction in skeletal muscle partially via promoting mitochondrial biogenesis [63]. Further study showed that the function of BBR on mitochondrion was inhibited in SIRT1 knocked-down cells, which suggested that SIRT1 may regulate the effect of BBR on mitochondrion [63]. It seems that BBR has a paradoxical effect on mitochondrion. Interestingly, living cells grow normally even in the absence of complex I activity in vitro [60], which may partly account for the paradoxical effect of BBR on mitochondrion. Nevertheless, the reason why cells grow normally in the absence of complex I activity is unclear, which should be further explored.

Uncoupling protein-2 (UCP2), a mitochondrial inner membrane carrier protein, is expressed at a low level in normal hepatocytes and at a high level in Kupffer cells [64]. Like UCP1, UCP2 is associated with heat production by inhibiting mitochondrial respiration via mediating proton leaking, thus reducing ATP synthesis. Study shows that UCP2 is associated with fat accumulation, oxidative stress, insulin resistance, and increased serum fatty acid level [65-67]. Increased oxidative stress and ROS induced the expression of UPC2 in mice with NAFLD [67]. UCP2 expression is increased in high-fat diet-fed rats and administration of BBR reduces the expression of UCP2 mRNA and protein [68]. However, further evidence suggests that upregulation of UCP2 in hepatocytes also improves the condition of NAFLD. The UCP2-866 A/A genotype in human induces hepatic UCP2 expression, but decreases the risk of nonalcoholic steatohepatitis [69]. So, why do both upregulation and downregulation of UCP2 expression lead to prevention of NAFLD? Is UCP2 really required for the effect of BBR on NAFLD (Figure 2G)?

\subsection{BBR Reduces Serum Cholesterol via A Distinctive Mechanism}

Distinct from statins, the cholesterol-lowering effect of BBR is through stabilization of low-density lipoprotein receptor (LDLR) mRNA independent of SREBP [70]. The prolonged existence of LDLR mRNA increases the expression of LDLR, thus leading to increased cholesterol catabolism. Additional evidence elucidates that the effect of stabilization of LDLR mRNA induced by BBR is dependent on extracellular signal-regulated kinase (ERK) activation (Figure 2H) [70].

\subsection{The New Role of BBR in Gut Microenvironment}

It is well known that BBR possesses antimicrobial activity, which is used to treat diarrhea and gut infections. Evidence indicates that the regulation of BBR on gut microenvironment may partially account for the improved NAFLD condition (Figure 2I). Treatment of BBR regulates intestinal microbiota, reduces fat absorbing, and decreases inflammation through reducing the entry of exogenous antigens and enhancing short-chain fatty acid in the gut [71,72]. Besides, impaired gut 
permeability is repaired by BBR via reverting damaged tight junctions in intestinal epithelium [73,74]. However, the mechanism underlying these phenomena is not completely known.

\subsection{Other Potential Mechanisms}

PCSK9 (encoding proprotein convertase subtilisin/kexin type 9) was discovered as a third locus associated with autosomal dominant hypercholesterolemia in 2003 [75]. Neural apoptosis regulated convertase-1 (NARC-1), encoded by PCSK9, is highly expressed in the liver and associated with cholesterol homeostasis [75]. Mutant of PCSK9 is associated with lifelong reduced serum LDL cholesterol (LDL-c), leading to decreased risk of cardiovascular events [76]. Evidence showed that PCSK9 expression was decreased in high-fat diet and BBR-fed mice, suggesting PCSK9 may be a new molecular target of BBR [77]. In addition, the metabolic profiles containing sphingomyelin (SM), phosphatidylcholine (PC), lysophosphatidylcholine (LysoPC), 13-hydroperoxy-9, 11-octadecadienoic acid (13-HpODE), eicosatrienoic acid, docosatrienoic acid, eicosenoic acid, glucose, maltose, and cholesterol change after BBR treatment $[78,79]$.

As the development of bioinformatics, new methods and technologies enable us to gain insight into the genetic mechanism of BBR in the treatment of NAFLD, uncovering another new aspect of BBR function. Recent study conducted by our department using the methods of bioinformatics showed that the expression of 881 mRNAs and 538 long noncoding RNAs (lncRNAs) was restored by treatment of BBR in the steatotic liver [80]. Among them, a significant association was found between a conserved lncRNA, MRAK052686, and antioxidant factor nuclear respiratory factor 2 (Nrf2) [80]. Treatment of BBR increased both MRAK052686 and Nrf2 expression [80]. These findings indicate that BBR improves NAFLD via a global modulation of hepatic mRNA and lncRNA expression profiles [80].

Additionally, DNA demethylation is also involved in the mechanism of BBR. We demonstrated that the methylation of microsomal triglyceride transfer protein (MTTP) promoter was decreased and the expression of MTTP is increased by BBR in rats [81]. MTTP locates in ER and is associated with VLDL assembly. Then, increased expression of MTTP promoted VLDL assembly and secretion, thus leading to improved NAFLD [81]. However, the precise mechanism of it is not conclusively determined (Figure 2J).

\section{Future Perspective}

Although no drug is approved in pharmacological therapy for NAFLD, the promising effect of BBR manifested both in animal experiments and clinical trials makes it a candidate for future pharmacological therapy against NAFLD. Lifestyle modification such as weight loss through calorie restriction and exercise does have beneficial effects on NAFLD. However, the mechanisms behind it are not completely uncovered. Both lifestyle modification and berberine can improve insulin resistance, regulate intestinal microbiota, upregulate energy consumption, and reduce serum cholesterol level, but they may work via different pathways. For instance, physical activity increases energy consumption mainly via increasing the demand of energy, while berberine increases energy consumption mainly via promoting fatty acid oxidation. Dietary intervention improves NAFLD via reducing the input of TGs, which is different from berberine. Berberine improves NAFLD via inhibiting lipogenesis, which is different from dietary intervention. Lifestyle modification simprove the condition of NAFLD, but are limited by sustainability due to patient motivation and difficulty with adherence. Lifestyle modification alone is not enough to revert NAFLD in serious conditions. In order to facilitate the process of BBR clinical application, there are still a number of issues to be solved: (a) The mechanisms of BBR in the treatment of NAFLD and the pathogenesis of NAFLD should be further investigated, especially in immunology and the gut microenvironment. Recent study suggested that dysfunction of lipid metabolism regulation in NAFLD promoted hepatocarcinogenesis via inducing a selective loss of $\mathrm{CD}^{+} \mathrm{T}$ lymphocytes in liver and impairing anti-tumor surveillance [82]. However, few studies have conducted research about the association between effect of BBR on NAFLD and immunity so far; (b) To increase the effect and reduce the side effect of BBR, although evidence indicates that BBR induced 
adverse effects are mild and tolerant [27-29,83], development of appropriate berberine derivative may be required. To date, some berberine derivatives have already been investigated [84,85]; (c) Drug combination is another alternative strategy to enhance the effect of BBR. Combination of BBR and plant stanols shows a synergistic effect on deceasing serum cholesterol in rats [86]. However, be well aware of the drug interactions; (d) Other factors containing route of administration and drug dose should be considered.

Acknowledgments: The authors thank the financial support of National Natural Science Foundation of China (81471073), Shanghai Science and Technology Committee (13441900303) and Excellent Member Program of Zhongshan Hospital Fudan University (2015ZSYXGG15).

Author Contributions: X.Z. performed the preparation and analysis of the data. X.Z., H.B., and X.G. wrote and edited the manuscript.

Conflicts of Interest: The authors declare no conflict of interest.

\section{References}

1. Cohen, J.C.; Horton, J.D.; Hobbs, H.H. Human fatty liver disease: Old questions and new insights. Science 2011, 332, 1519-1523. [CrossRef] [PubMed]

2. Kotronen, A.; Yki-Jarvinen, H. Fatty liver: A novel component of the metabolic syndrome. Arterioscler. Thromb. Vasc. Biol. 2008, 28, 27-38. [CrossRef] [PubMed]

3. Chalasani, N.; Younossi, Z.; Lavine, J.E.; Diehl, A.M.; Brunt, E.M.; Cusi, K.; Charlton, M.; Sanyal, A.J. The diagnosis and management of non-alcoholic fatty liver disease: Practice guideline by the american association for the study of liver diseases, american college of gastroenterology, and the american gastroenterological association. Hepatology 2012, 55, 2005-2023. [CrossRef] [PubMed]

4. Vanni, E.; Bugianesi, E.; Kotronen, A.; de Minicis, S.; Yki-Jarvinen, H.; Svegliati-Baroni, G. From the metabolic syndrome to NAFLD or vice versa? Dig. Liver Dis. 2010, 42, 320-330. [CrossRef] [PubMed]

5. Younossi, Z.M.; Otgonsuren, M.; Henry, L.; Venkatesan, C.; Mishra, A.; Erario, M.; Hunt, S. Association of non-alcoholic fatty liver disease (NAFLD) with hepatocellular carcinoma (HCC) in the united states from 2004-2009. Hepatology 2015, 62, 1723-1730. [CrossRef] [PubMed]

6. Mittal, S.; El-Serag, H.B. Epidemiology of hepatocellular carcinoma: Consider the population. J. Clin. Gastroenterol. 2013, 47. [CrossRef] [PubMed]

7. Mittal, S.; El-Serag, H.B.; Sada, Y.H.; Kanwal, F.; Duan, Z.G.; Temple, S.; May, S.B.; Kramer, J.R.; Richardson, P.A.; Davila, J.A. Hepatocellular carcinoma in the absence of cirrhosis in united states veterans is associated with nonalcoholic fatty liver disease. Clin. Gastroenterol. Hepatol. 2016, 14, 124-131. [CrossRef] [PubMed]

8. Kanwal, F.; Kramer, J.R.; Duan, Z.G.; Yu, X.Y.; White, D.; El-Serag, H.B. Trends in the burden of nonalcoholic fatty liver disease in a united states cohort of veterans. Clin. Gastroenterol. Hepatol. 2016, 14, 301-308. [CrossRef] [PubMed]

9. Armstrong, M.J.; Adams, L.A.; Canbay, A.; Syn, W.K. Extrahepatic complications of nonalcoholic fatty liver disease. Hepatology 2014, 59, 1174-1197. [CrossRef] [PubMed]

10. Cicero, A.F.; Ertek, S. Metabolic and cardiovascular effects of berberine: From preclinical evidences to clinical trial results. Clin. Lipidol. 2009, 4, 553-563. [CrossRef]

11. Wong, V.W.S.; Wong, G.L.H.; Tsang, S.W.C.; Fan, T.; Chu, W.C.W.; Woo, J.; Chan, A.W.H.; Choi, P.C.L.; Chim, A.M.L.; Lau, J.Y.W.; et al. High prevalence of colorectal neoplasm in patients with non-alcoholic steatohepatitis. Gut 2011, 60, 829-836. [CrossRef] [PubMed]

12. Lavine, J.E.; Schwimmer, J.B.; van Natta, M.L.; Molleston, J.P.; Murray, K.F.; Rosenthal, P.; Abrams, S.H.; Scheimann, A.O.; Sanyal, A.J.; Chalasani, N.; et al. Effect of vitamin E or metformin for treatment of nonalcoholic fatty liver disease in children and adolescents the tonic randomized controlled trial. J. Am. Med. Assoc. 2011, 305, 1659-1668. [CrossRef] [PubMed]

13. Gouni-Berthold, I.; Papanas, N.; Maltezos, E. The role of oral antidiabetic agents and incretin mimetics in type 2 diabetic patients with non-alcoholic fatty liver disease. Curr. Pharm. Des. 2014, 20, 3705-3715. [CrossRef] [PubMed]

14. Ratziu, V. Starting the battle to control non-alcoholic steatohepatitis. Lancet 2015, 385, 922-924. [CrossRef] 
15. Neuschwander-Tetri, B.A.; Loomba, R.; Sanyal, A.J.; Lavine, J.E.; van Natta, M.L.; Abdelmalek, M.F.; Chalasani, N.; Dasarathy, S.; Diehl, A.M.; Hameed, B.; et al. Farnesoid x nuclear receptor ligand obeticholic acid for non-cirrhotic, non-alcoholic steatohepatitis (flint): A multicentre, randomised, placebo-controlled trial. Lancet 2015, 385, 956-965. [CrossRef]

16. Tillhon, M.; Ortiz, L.M.G.; Lombardi, P.; Scovassi, A.I. Berberine: New perspectives for old remedies. Biochem. Pharmacol. 2012, 84, 1260-1267. [CrossRef] [PubMed]

17. Birdsall, T.C.; Kelly, G.S. Berberine: Therapeutic potential of an alkaloid found in several medicinal plants. Altern. Med. Rev. 1997, 2, 94-103.

18. Vuddanda, P.R.; Chakraborty, S.; Singh, S. Berberine: A potential phytochemical with multispectrum therapeutic activities. Expert Opin. Investig. Drugs 2010, 19, 1297-1307. [CrossRef] [PubMed]

19. Kulkarni, S.K.; Dhir, A. Berberine: A plant alkaloid with therapeutic potential for central nervous system disorders. Phytother. Res. 2010, 24, 317-324. [CrossRef] [PubMed]

20. Williams, K.H.; Shackel, N.A.; Gorrell, M.D.; McLennan, S.V.; Twigg, S.M. Diabetes and nonalcoholic fatty liver disease: A pathogenic duo. Endocr. Rev. 2013, 34, 84-129. [CrossRef] [PubMed]

21. Chong, M.F.F.; Fielding, B.A.; Frayn, K.N. Mechanisms for the acute effect of fructose on postprandial lipemia. Am. J. Clin. Nutr. 2007, 85, 1511-1520. [PubMed]

22. Baidal, J.A.W.; Lavine, J.E. The intersection of nonalcoholic fatty liver disease and obesity. Sci. Transl. Med. 2016, 8. [CrossRef] [PubMed]

23. Rinella, M.E. Nonalcoholic fatty liver disease a systematic review. J. Am. Med. Assoc. 2015, 313, $2263-2273$. [CrossRef] [PubMed]

24. Miele, L.; Valenza, V.; la Torre, G.; Montalto, M.; Cammarota, G.; Ricci, R.; Masciana, R.; Forgione, A.; Gabrieli, M.L.; Perotti, G.; et al. Increased intestinal permeability and tight junction alterations in nonalcoholic fatty liver disease. Hepatology 2009, 49, 1877-1887. [CrossRef] [PubMed]

25. Gaebele, E.; Dostert, K.; Hofmann, C.; Wiest, R.; Schoelmerich, J.; Hellerbrand, C.; Obermeier, F. DSS induced colitis increases portal LPS levels and enhances hepatic inflammation and fibrogenesis in experimental NASH. J. Hepatol. 2011, 55, 1391-1399. [CrossRef] [PubMed]

26. Rivera, C.A.; Adegboyega, P.; van Rooijen, N.; Tagalicud, A.; Allman, M.; Wallace, M. Toll-like receptor-4 signaling and kupffer cells play pivotal roles in the pathogenesis of non-alcoholic steatohepatitis. J. Hepatol. 2007, 47, 571-579. [CrossRef] [PubMed]

27. Hu, Y.S.; Ehli, E.A.; Kittelsrud, J.; Ronan, P.J.; Munger, K.; Downey, T.; Bohlen, K.; Callahan, L.; Munson, V.; Jahnke, M.; et al. Lipid-lowering effect of berberine in human subjects and rats. Phytomedicine 2012, 19, 861-867. [CrossRef] [PubMed]

28. Derosa, G.; D’Angelo, A.; Bonaventura, A.; Bianchi, L.; Romano, D.; Maffioli, P. Effects of berberine on lipid profile in subjects with low cardiovascular risk. Expert Opin. Biol.Ther. 2013, 13, 475-482. [CrossRef] [PubMed]

29. Yan, H.M.; Xia, M.F.; Wang, Y.; Chang, X.X.; Yao, X.Z.; Rao, S.X.; Zeng, M.S.; Tu, Y.F.; Feng, R.; Jia, W.P.; et al. Efficacy of berberine in patients with non-alcoholic fatty liver disease. PLoS ONE 2015, 10, e0134172. [CrossRef] [PubMed]

30. Liu, Y.; Zhang, L.; Song, H.Y.; Ji, G. Update on berberine in nonalcoholic fatty liver disease. Evid. Based Complement. Altern. Med. 2013, 2013. [CrossRef] [PubMed]

31. Brown, M.S.; Goldstein, J.L. Selective versus total insulin resistance: A pathogenic paradox. Cell Metab. 2008, 7, 95-96. [CrossRef] [PubMed]

32. Lee, Y.S.; Kim, W.S.; Kim, K.H.; Yoon, M.J.; Cho, H.J.; Shen, Y.; Ye, J.M.; Lee, C.H.; Oh, W.K.; Kim, C.T.; et al. Berberine, a natural plant product, activates amp-activated protein kinase with beneficial metabolic effects in diabetic and insulin-resistant states. Diabetes 2006, 55, 2256-2264. [CrossRef] [PubMed]

33. Li, Y.; Xu, S.; Mihaylova, M.M.; Zheng, B.; Hou, X.; Jiang, B.; Park, O.; Luo, Z.; Lefai, E.; Shyy, J.Y.J.; et al. Ampk phosphorylates and inhibits srebp activity to attenuate hepatic steatosis and atherosclerosis in diet-induced insulin-resistant mice. Cell Metab. 2011, 13, 376-388. [CrossRef] [PubMed]

34. Liu, X.; Li, G.; Zhu, H.; Huang, L.; Liu, Y.; Ma, C.; Qin, C. Beneficial effect of berberine on hepatic insulin resistance in diabetic hamsters possibly involves in $\mathrm{SREBP}_{\mathrm{S}}, \mathrm{LXR}_{\alpha}$ and $\mathrm{PPAR}_{\alpha}$ transcriptional programs. Endocr. J. 2010, 57, 881-893. [CrossRef] [PubMed] 
35. Chen, Y.F.; Li, Y.; Wang, Y.W.; Wen, Y.; Sun, C.H. Berberine improves free-fatty-acid-induced insulin resistance in 16 myotubes through inhibiting peroxisome proliferator-activated receptor gamma and fatty acid transferase expressions. Metab. Clin. Exp. 2009, 58, 1694-1702. [CrossRef] [PubMed]

36. Kong, W.J.; Zhang, H.; Song, D.Q.; Xue, R.; Zhao, W.; Wei, J.; Wang, Y.M.; Shan, N.; Zhou, Z.X.; Yang, P.; et al. Berberine reduces insulin resistance through protein kinase c-dependent up-regulation of insulin. Receptor expression. Metab. Clin. Exp. 2009, 58, 109-119. [CrossRef] [PubMed]

37. Lou, T.J.; Zhang, Z.G.; Xi, Z.L.; Liu, K.; Li, L.; Liu, B.L.; Huang, F. Berberine inhibits inflammatory response and ameliorates insulin resistance in hepatocytes. Inflammation 2011, 34, 659-667. [CrossRef] [PubMed]

38. Xing, L.J.; Zhang, L.; Liu, T.; Hua, Y.Q.; Zheng, P.Y.; Ji, G. Berberine reducing insulin resistance by up-regulating IRS-2 mRNA expression in nonalcoholic fatty liver disease (NAFLD) rat liver. Eur. J. Pharmacol. 2011, 668, 467-471. [CrossRef] [PubMed]

39. Leng, S.H.; Lu, F.E.; Xu, L.J. Therapeutic effects of berberine in impaired glucose tolerance rats and its influence on insulin secretion. Acta Pharmacol. Sin. 2004, 25, 496-502. [PubMed]

40. Yamauchi, T.; Kamon, J.; Waki, H.; Terauchi, Y.; Kubota, N.; Hara, K.; Mori, Y.; Ide, T.; Murakami, K.; Tsuboyama-Kasaoka, N.; et al. The fat-derived hormone adiponectin reverses insulin resistance associated with both lipoatrophy and obesity. Nat. Med. 2001, 7, 941-946. [CrossRef] [PubMed]

41. Yamauchi, T.; Kamon, J.; Minokoshi, Y.; Ito, Y.; Waki, H.; Uchida, S.; Yamashita, S.; Noda, M.; Kita, S.; Ueki, K.; et al. Adiponectin stimulates glucose utilization and fatty-acid oxidation by activating amp-activated protein kinase. Nat. Med. 2002, 8, 1288-1295. [CrossRef] [PubMed]

42. Waki, H.; Yamauchi, T.; Kamon, J.; Ito, Y.; Uchida, S.; Kita, S.; Hara, K.; Hada, Y.; Vasseur, F.; Froguel, P.; et al. Impaired multimerization of human adiponectin mutants associated with diabetes-Molecular structure and multimer formation of adiponectin. J. Biol. Chem. 2003, 278, 40352-40363. [CrossRef] [PubMed]

43. Pajvani, U.B.; Du, X.L.; Combs, T.P.; Berg, A.H.; Rajala, M.W.; Schulthess, T.; Engel, J.; Brownlee, M.; Scherer, P.E. Structure-function studies of the adipocyte-secreted hormone ACRP30/adiponectinImplications for metabolic regulation and bioactivity. J. Biol. Chem. 2003, 278, 9073-9085. [CrossRef] [PubMed]

44. Li, Y.; Wang, P.C.; Zhuang, Y.; Lin, H.; Li, Y.H.; Liu, L.; Meng, Q.H.; Cui, T.; Liu, J.; Li, Z. Activation of ampk by berberine promotes adiponectin multimerization in 3T3-L1 adipocytes. Febs Lett. 2011, 585, 1735-1740. [CrossRef] [PubMed]

45. Kuo, C.L.; Chi, C.W.; Liu, T.Y. The anti-inflammatory potential of berberine in vitro and in vivo. Cancer Lett. 2004, 203, 127-137. [CrossRef] [PubMed]

46. Guo, T.; Woo, S.L.; Guo, X.; Li, H.G.; Zheng, J.; Botchlett, R.; Liu, M.Y.; Pei, Y.; Xu, H.; Cai, Y.L.; et al. Berberine ameliorates hepatic steatosis and suppresses liver and adipose tissue inflammation in mice with diet-induced obesity. Sci. Rep. 2016, 6. [CrossRef] [PubMed]

47. Wang, Z.-S.; Lu, F.-E.; Xu, L.-J.; Dong, H. Berberine reduces endoplasmic reticulum stress and improves insulin signal transduction in Hep G2 cells. Acta Pharmacol. Sin. 2010, 31, 578-584. [CrossRef] [PubMed]

48. Zhang, Z.G.; Li, B.; Meng, X.J.; Yao, S.S.; Jin, L.N.; Yang, J.; Wang, J.Q.; Zhang, H.Z.; Zhang, Z.J.; Cai, D.S.; et al. Berberine prevents progression from hepatic steatosis to steatohepatitis and fibrosis by reducing endoplasmic reticulum stress. Sci. Rep. 2016, 6. [CrossRef] [PubMed]

49. Larsen, P.J.; Jensen, P.B.; Sorensen, R.V.; Larsen, L.K.; Vrang, N.; Wulff, E.M.; Wassermann, K. Differential influences of peroxisonte proliferator-activated receptors gamma and $-\alpha$ on food intake and energy homeostasis. Diabetes 2003, 52, 2249-2259. [CrossRef] [PubMed]

50. Yang, J.; Yin, J.H.; Gao, H.F.; Xu, L.X.; Wang, Y.; Xu, L.; Li, M. Berberine improves insulin sensitivity by inhibiting fat store and adjusting adipokines profile in human preadipocytes and metabolic syndrome patients. Evid. Based Complement. Altern. Med. 2012, 2012. [CrossRef] [PubMed]

51. Kahn, B.B.; Alquier, T.; Carling, D.; Hardie, D.G. Amp-activated protein kinase: Ancient energy gauge provides clues to modern understanding of metabolism. Cell Metab. 2005, 1, 15-25. [CrossRef] [PubMed]

52. Hardie, D.G. AMP-activated/SNF1 protein kinases: Conserved guardians of cellular energy. Nat. Rev. Mol. Cell Biol. 2007, 8, 774-785. [CrossRef] [PubMed]

53. Krishan, S.; Richardson, D.R.; Sahni, S. Adenosine monophosphate-activated kinase and its key role in catabolism: Structure, regulation, biological activity, and pharmacological activation. Mol. Pharmacol. 2015, 87, 363-377. [CrossRef] [PubMed] 
54. Kim, W.S.; Lee, Y.S.; Cha, S.H.; Jeong, H.W.; Choe, S.S.; Lee, M.R.; Oh, G.T.; Park, H.S.; Lee, K.U.; Lane, M.D.; et al. Berberine improves lipid dysregulation in obesity by controlling central and peripheral ampk activity. Am. J. Physiol. Endocrinol. Metab. 2009, 296, E812-E819. [CrossRef] [PubMed]

55. Brusq, J.M.; Ancellin, N.; Grondin, P.; Guillard, R.; Martin, S.; Saintillan, Y.; Issandou, M. Inhibition of lipid synthesis through activation of amp kinase: An additional mechanism for the hypolipidemic effects of berberine. J. Lipid Res. 2006, 47, 1281-1288. [CrossRef] [PubMed]

56. Turner, N.; Li, J.Y.; Gosby, A.; To, S.W.C.; Cheng, Z.; Miyoshi, H.; Taketo, M.M.; Cooney, G.J.; Kraegen, E.W.; James, D.E.; et al. Berberine and its more biologically available derivative, dihydroberberine, inhibit mitochondrial respiratory complex I: A mechanism for the action of berberine to activate AMP-activated protein kinase and improve insulin action. Diabetes 2008, 57, 1414-1418. [CrossRef] [PubMed]

57. Woods, A.; Johnstone, S.R.; Dickerson, K.; Leiper, F.C.; Fryer, L.G.D.; Neumann, D.; Schlattner, U.; Wallimann, T.; Carlson, M.; Carling, D. LKB1 is the upstream kinase in the amp-activated protein kinase cascade. Curr. Biol. 2003, 13, 2004-2008. [CrossRef] [PubMed]

58. Hawley, S.A.; Pan, D.A.; Mustard, K.J.; Ross, L.; Bain, J.; Edelman, A.M.; Frenguelli, B.G.; Hardie, D.G. Calmodulin-dependent protein kinase kinase- $\beta$ is an alternative upstream kinase for AMP-activated protein kinase. Cell Metab. 2005, 2, 9-19. [CrossRef] [PubMed]

59. Momcilovic, M.; Hong, S.-P.; Carlson, M. Mammalian TAK1 activates SNF1 protein kinase in yeast and phosphorylates AMP-activated protein kinase in vitro. J. Biol. Chem. 2006, 281, 25336-25343. [CrossRef] [PubMed]

60. Xu, M.; Xiao, Y.Y.; Yin, J.; Hou, W.L.; Yu, X.Y.; Shen, L.; Liu, F.; Wei, L.; Jia, W.P. Berberine promotes glucose consumption independently of AMP-activated protein kinase activation. PLoS ONE 2014, 9, e103702. [CrossRef] [PubMed]

61. Cao, S.J.; Zhou, Y.; Xu, P.X.; Wang, Y.; Yan, J.K.; Bin, W.; Qiu, F.; Kang, N. Berberine metabolites exhibit triglyceride-lowering effects via activation of AMP-activated protein kinase in Hep G2 cells. J. Ethnopharmacol. 2013, 149, 576-582. [CrossRef] [PubMed]

62. Teodoro, J.S.; Duarte, F.V.; Gomes, A.P.; Varela, A.T.; Peixoto, F.M.; Rolo, A.P.; Palmeira, C.M. Berberine reverts hepatic mitochondrial dysfunction in high-fat fed rats: A possible role for SIRT3 activation. Mitochondrion 2013, 13, 637-646. [CrossRef] [PubMed]

63. Gomes, A.P.; Duarte, F.V.; Nunes, P.; Hubbard, B.P.; Teodoro, J.S.; Varela, A.T.; Jones, J.G.; Sinclair, D.A.; Palmeira, C.M.; Rolo, A.P. Berberine protects against high fat diet-induced dysfunction in muscle mitochondria by inducing SIRT1-dependent mitochondrial biogenesis. Biochim. Biophys. Acta 2012, 1822, 185-195. [CrossRef] [PubMed]

64. Larrouy, D.; Laharrague, P.; Carrera, G.; ViguerieBascands, N.; LeviMeyrueis, C.; Fleury, C.; Pecqueur, C.; Nibbelink, M.; Andre, M.; Casteilla, L.; et al. Kupffer cells are a dominant site of uncoupling protein 2 expression in rat liver. Biochem. Biophys. Res. Commun. 1997, 235, 760-764. [CrossRef] [PubMed]

65. Baffy, G. Uncoupling protein-2 and non-alcoholic fatty liver disease. Front. Biosci. 2005, 10, 2082-2096. [CrossRef] [PubMed]

66. Jin, X.; Xiang, Z.; Chen, Y.-P.; Ma, K.-F.; Ye, Y.-F.; Li, Y.-M. Uncoupling protein and nonalcoholic fatty liver disease. Chin. Med. J. 2013, 126, 3151-3155. [PubMed]

67. Yang, S.; Zhu, H.; Li, Y.; Lin, H.; Gabrielson, K.; Trush, M.A.; Diehl, A.M. Mitochondrial adaptations to obesity-related oxidant stress. Arch. Biochem. Biophys. 2000, 378, 259-268. [CrossRef] [PubMed]

68. Yang, Q.H.; Hu, S.P.; Zhang, Y.P.; Xie, W.N.; Li, N.; Ji, G.Y.; Qiao, N.L.; Lin, X.F.; Chen, T.Y.; Liu, H.T. Effect of berberine on expressions of uncoupling protein-2 mRNA and protein in hepatic tissue of non-alcoholic fatty liver disease in rats. Chin. J. Integr. Med. 2011, 17, 205-211. [CrossRef] [PubMed]

69. Fares, R.; Petta, S.; Lombardi, R.; Grimaudo, S.; Dongiovanni, P.; Pipitone, R.; Rametta, R.; Fracanzani, A.L.; Mozzi, E.; Craxi, A.; et al. The UCP2-866 G>A promoter region polymorphism is associated with nonalcoholic steatohepatitis. Liver Int. 2015, 35, 1574-1580. [CrossRef] [PubMed]

70. Kong, W.J.; Wei, J.; Abidi, P.; Lin, M.H.; Inaba, S.; Li, C.; Wang, Y.L.; Wang, Z.Z.; Si, S.Y.; Pan, H.N.; et al. Berberine is a novel cholesterol-lowering drug working through a unique mechanism distinct from statins. Nat. Med. 2004, 10, 1344-1351. [CrossRef] [PubMed]

71. Backhed, F.; Ding, H.; Wang, T.; Hooper, L.V.; Koh, G.Y.; Nagy, A.; Semenkovich, C.F.; Gordon, J.I. The gut microbiota as an environmental factor that regulates fat storage. Proc. Natl. Acad. Sci. USA 2004, 101, 15718-15723. [CrossRef] [PubMed] 
72. Zhang, X.; Zhao, Y.; Zhang, M.; Pang, X.; Xu, J.; Kang, C.; Li, M.; Zhang, C.; Zhang, Z.; Zhang, Y.; et al. Structural changes of gut microbiota during berberine-mediated prevention of obesity and insulin resistance in high-fat diet-fed rats. PLoS ONE 2012, 7, e42529. [CrossRef] [PubMed]

73. Gu, L.; Li, N.; Li, Q.; Zhang, Q.; Wang, C.; Zhu, W.; Li, J. The effect of berberine in vitro on tight junctions in human CACO-2 intestinal epithelial cells. Fitoterapia 2009, 80, 241-248. [CrossRef] [PubMed]

74. Gu, L.; Li, N.; Gong, J.; Li, Q.; Zhu, W.; Li, J. Berberine ameliorates intestinal epithelial tight-junction damage and down-regulates myosin light chain kinase pathways in a mouse model of endotoxinemia. J. Infect. Dis. 2011, 203, 1602-1612. [CrossRef] [PubMed]

75. Abifadel, M.; Varret, M.; Rabes, J.P.; Allard, D.; Ouguerram, K.; Devillers, M.; Cruaud, C.; Benjannet, S.; Wickham, L.; Erlich, D.; et al. Mutations in PCSK9 cause autosomal dominant hypercholesterolemia. Nat. Genet. 2003, 34, 154-156. [CrossRef] [PubMed]

76. Cohen, J.C.; Boerwinkle, E.; Mosley, T.H.; Hobbs, H.H. Sequence variations in PCSK9, low LDL, and protection against coronary heart disease. N. Engl. J. Med. 2006, 354, 1264-1272. [CrossRef] [PubMed]

77. Liu, D.L.; Xu, L.J.; Dong, H.; Chen, G.; Huang, Z.Y.; Zou, X.; Wang, K.F.; Luo, Y.H.; Lu, F.E. Inhibition of proprotein convertase subtilisin/kexin type 9: A novel mechanism of berberine and 8-hydroxy dihydroberberine against hyperlipidemia. Chin. J. Integr. Med. 2015, 21, 132-138. [CrossRef] [PubMed]

78. Li, J.; Liu, Z.Z.; Guo, M.X.; Xu, K.J.; Jiang, M.; Lu, A.P.; Gao, X.Y. Metabolomics profiling to investigate the pharmacologic mechanisms of berberine for the treatment of high-fat diet-induced nonalcoholic steatohepatitis. Evid. Based Complement. Altern. Med. 2015, 2015. [CrossRef] [PubMed]

79. Jiang, Z.J.; Liu, F.; Ong, E.S.; Li, S.F.Y. Metabolic profile associated with glucose and cholesterol lowering effects of berberine in sprague-dawley rats. Metabolomics 2012, 8, 1052-1068. [CrossRef]

80. Yuan, X.L.; Wang, J.; Tang, X.Y.; Li, Y.X.; Xia, P.; Gao, X. Berberine ameliorates nonalcoholic fatty liver disease by a global modulation of hepatic mRNA and lncRNA expression profiles. J. Transl. Med. 2015, 13, 24. [CrossRef] [PubMed]

81. Chang, X.X.; Yan, H.M.; Fei, J.; Jiang, M.H.; Zhu, H.G.; Lu, D.R.; Gao, X. Berberine reduces methylation of the mttp promoter and alleviates fatty liver induced by a high-fat diet in rats. J. Lipid Res. 2010, 51, 2504-2515. [CrossRef] [PubMed]

82. Ma, C.; Kesarwala, A.H.; Eggert, T.; Medina-Echeverz, J.; Kleiner, D.E.; Jin, P.; Stroncek, D.F.; Terabe, M.; Kapoor, V.; ElGindi, M.; et al. NAFLD causes selective $\mathrm{CD}^{+} \mathrm{T}$ lymphocyte loss and promotes hepatocarcinogenesis. Nature 2016, 531, 253-257. [CrossRef] [PubMed]

83. Perez-Rubio, K.G.; Gonzalez-Ortiz, M.; Martinez-Abundis, E.; Robles-Cervantes, J.A.; Espinel-Bermudez, M.C. Effect of berberine administration on metabolic syndrome, insulin sensitivity, and insulin secretion. Metab. Syndr. Relat. Disord. 2013, 11, 366-369. [CrossRef] [PubMed]

84. Wang, Y.X.; Kong, W.J.; Li, Y.H.; Tang, S.; Li, Z.; Li, Y.B.; Shan, Y.Q.; Bi, C.W.; Jiang, J.D.; Song, D.Q. Synthesis and structure-activity relationship of berberine analogues in LDLR up-regulation and AMPK activation. Bioorg. Med. Chem. 2012, 20, 6552-6558. [CrossRef] [PubMed]

85. Singh, I.P.; Mahajan, S. Berberine and its derivatives: A patent review (2009-2012). Expert Opin. Ther. Pat. 2013, 23, 215-231. [CrossRef] [PubMed]

86. Jia, X.M.; Chen, Y.F.; Zidichouski, J.; Zhang, J.Z.; Sun, C.H.; Wang, Y.W. Co-administration of berberine and plant stanols synergistically reduces plasma cholesterol in rats. Atherosclerosis 2008, 201, 101-107. [CrossRef] [PubMed]

(C) 2016 by the authors; licensee MDPI, Basel, Switzerland. This article is an open access article distributed under the terms and conditions of the Creative Commons Attribution (CC-BY) license (http:/ / creativecommons.org/licenses/by/4.0/). 